\title{
Depression, anxiety, and stress in oral lichen planus: a systematic review and meta-analysis
}

\author{
Teresa De Porras-Carrique ${ }^{1,2} \cdot$ Miguel Ángel González-Moles $^{1,2,3} \cdot$ Saman Warnakulasuriya ${ }^{3,4} \cdot$ Pablo Ramos-García ${ }^{1,2}$
}

Received: 25 May 2021 / Accepted: 29 July 2021 / Published online: 30 August 2021

(c) The Author(s) 2021, corrected publication 2022

\begin{abstract}
Objectives We present this systematic review and meta-analyses to evaluate current evidence on the prevalence of depression, anxiety, and stress in patients with oral lichen planus and their magnitude of association.

Material and methods We searched PubMed, Embase, Web of Science, Scopus, PsycInfo, and Google Scholar for studies published before January 2021. We evaluated the quality of studies using a specific method for systematic reviews addressing prevalence questions, designed by the Joanna Briggs Institute. We carried out meta-analyses and performed heterogeneity, subgroups, meta-regression, and small-study effects analyses.

Results Fifty-one studies (which recruited 6,815 patients) met the inclusion criteria. Our results reveal a high prevalence of depression $(31.19 \%)$, anxiety $(54.76 \%)$, and stress $(41.10 \%)$ in oral lichen planus. Furthermore, OLP patients presented a significantly higher relative frequency than control group without OLP for depression $(\mathrm{OR}=6.15,95 \% \mathrm{CI}=2.73-13.89$, $p<0.001)$, anxiety $(\mathrm{OR}=3.51,95 \% \mathrm{CI}=2.10-5.85, p<0.001)$, and stress $(\mathrm{OR}=3.64,95 \% \mathrm{CI}=1.48-8.94, p=0.005)$, showing large effect sizes. Subgroups meta-analyses showed the relevance of the participation of psychologists and psychiatrists in the diagnosis of depression, anxiety, and stress in patients with OLP. Multivariable meta-regression analysis showed the importance of the comorbidity of depression-anxiety in patients with OLP.

Conclusions Our systematic review and meta-analysis show that patients with OLP suffer a higher prevalence of depression, anxiety, and stress, being more frequent than in general population.

Clinical relevance

In the dental clinic, especially dentists should be aware of depression, anxiety, and stress in OLP patients to achieve a correct referral.
\end{abstract}

Keywords Oral lichen planus $\cdot$ Depression $\cdot$ Anxiety $\cdot$ Stress $\cdot$ Systematic review $\cdot$ Meta-analysis

\section{Introduction}

Oral lichen planus (OLP) is a chronic inflammatory autoimmune disease that presents with white reticular lesions accompanied or not by erythematous, erosive, plaque, bullous, or papular lesions [1]. The importance of the disease lies in its frequency, affecting $1 \%$ of the general population

Miguel Ángel González-Moles magonzal@ugr.es

1 School of Dentistry, University of Granada, Granada, Spain

2 Biohealth Research Institute (IBS), Granada, Spain

3 WHO Collaborating Centre for Oral Cancer, London, UK

4 Faculty of Dentistry, Oral and Craniofacial Sciences, King's College London, London, UK as recently has been documented, with a higher prevalence in Europe (1.38\%) [2]. Furthermore, OLP is now considered undoubtedly an oral potentially malignant disorder with a risk of progression to cancer in $2.28 \%$ of the affected population [1, 3-5].

A widely recognized and generally accepted feature of OLP is related to its possible association with some psychological disorders $[6,7]$ among which are essentially anxiety, depression, and stress [8-10]. A systematic review has reported the presence of psychological disorders in patients suffering from OLP [11], and more recently, a meta-analysis corroborates the association between cutaneous and oral lichen planus with depression and anxiety [12]. The aforementioned metaanalysis [12], the only one published to date, even being the work that provides the greatest scientific evidence on the subject, presents critically low methodological quality. As will 
be discussed later, there is significant bias in the selection of included papers that impacts on the strength of this review.

Encountering cases with OLP is not uncommon in clinical dental practice. The management of OLP has multiple aspects, all of which are important and complex, such as its chronic nature and consequently the frequent need to prescribe prolonged treatments with immunosuppressants, i.e., topical corticosteroids; its potential to evolve into oral cancer, requiring lifelong follow-up; its association with systemic diseases, among which are diabetes mellitus, hypertension, hepatitis $\mathrm{C}$, and some autoimmune diseases Hashimoto's thyroiditis and thymoma [13-17]; and also its association with psychological disorders. The recognition of psychological disorders in patients with OLP is especially complex due to the difficulty to exploring this aspect in the dental clinic. As a consequence of the reticence of many patients to reveal or recognize their psychiatric diseases, particularly if this topic is not specifically investigated, the patient will probably keep it hidden. Furthermore, many patients with OLP, even admitting to being subjected to an altered emotional state, have not previously been diagnosed by a psychologist or a psychiatrist. In addition, probably, it is likely that patients, due to fear of the adverse effects of the treatment or even embarrassment, do not make the decision to ask for medical advice. Finally, it must be recognized that many dentists may not feel authorized or qualified, or even not knowing how to refer a patient for a psychological evaluation. Another relevant dimension concerns the extent to which it could affect the emotional state of the patient with OLP to be informed of the risk of developing oral cancer.

All these questions justify carrying out a thorough investigation on the subject with the aim of knowing, based on scientific evidence, what is the real magnitude of the problem, what are the clinical aspects of a patient with OLP that should make the dentist suspect the presence of an associated psychological disorder, and what should be the attitude in the management of these patients in the dental clinic. To achieve these objectives, a systematic review and metaanalysis have been carried out to qualitatively and quantitatively evaluate the prevalence and magnitude of the association between OLP and psychological disorders, as well as the associated factors, following strict criteria validated in international consensus that guarantee obtaining of results based on scientific methodology leading to a high quality of evidence.

\section{Material and methods}

\section{Framework design}

This systematic review and meta-analysis closely followed the criteria of Cochrane Handbook for Systematic Reviews of Interventions [18] and Joanna Briggs Institute (University of Adelaide, Australia) for systematic reviews formulating focused questions of prevalence and for proportion metaanalyses. It was also designed, conducted, and validated according to A MeaSurement Tool to Assess systematic Reviews (AMSTAR2) high standards [19], and reporting complied with MOOSE and PRISMA guidelines [20, 21].

To assess the prevalence of mental disorders among OLP patients, Condition, Context and Population ( $\mathrm{CoCoPop}$ ) framework was designed: condition, proportion of cases with depression, anxiety, and/or stress, expressed as percentage; context, their associated characteristics (i.e., geographical area, suspicion method for depression, anxiety, and stress, specialist implied in the diagnosis of metal disorders, publication language, sex, age, tobacco, alcohol, type of OLP, year of publication, risk of bias, and human development index); population, participants with OLP diagnosed by clinical and/or histopathological criteria.

To assess the magnitude of association between mental disorders and OLP, PECOTS framework was designed: population, participants with OLP diagnosed by clinical and/or histopathological criteria; exposure, cases with depression, anxiety, and/or stress; comparison, healthy controls (i.e., non-affected by the precedent mental disorders); outcome, magnitude of association using odds ratios as effect size measure, with 95\% confidence intervals; timing, no restrictions by follow-up period or publication date; setting, observational studies published in any language.

\section{Protocol}

In order to minimize risk of bias and improve the transparency, precision, and integrity of our systematic review and meta-analysis, a protocol on its methodology has been a priori designed and submitted in PROSPERO International prospective register of systematic reviews (www.crd.york.ac. uk/PROSPERO; registration code CRD42020222371). Our protocol also complied with PRISMA-P statement in order to ensure scientific rigor [22].

\section{Search strategy}

We searched MEDLINE (through PubMed), Embase, PsycInfo, Web of Science, and Scopus databases for studies published before the search date (upper limit, January 2021), with no lower date limit. Searches were built to maximize sensitivity and combined thesaurus terms used by the databases (i.e., MeSH and Emtree) with free terms (Table 1, Appendix p.5). Only keywords synonyms or related to oral lichen planus were included, to retrieve the maximum number of possible registers. An additional screening was performed handsearching the reference lists of retrieved included studies and using Google. All references were 
managed using Mendeley v.1.19.4 (Elsevier, Amsterdam, The Netherlands); duplicates were also removed via this software.

\section{Eligibility criteria}

The inclusion criteria were the following: (1) original studies, without publication language (studies published in English [ $n=47]$, Chinese [ $n=1]$, French [ $n=1]$, Italian [ $n=1]$, and Spanish $[n=1]$ were identified and included) or date restrictions; (2) studies analyzing the prevalence of depression, anxiety, or stress in patients with OLP (with or without a control group), and/or the magnitude of association (control group needed); (3) observational study design; (4) when results derived from the same study population, we included the most recently reported or those providing more data; the use of the same population in different studies was determined by verifying the name and affiliation of authors, location of the study, source of patients, and recruitment period.

The exclusion criteria were the following: (1) retractions, reviews, meta-analyses, case reports, editorials, letters, meeting abstracts, personal comments, or book chapters; (2) animal research or in vitro studies; (3) absence of healthy control group for the magnitude of association analysis; (4) lack of essential data for statistical analyses; (5) presence of aggregated data for OLP and cutaneous or genital lichen planus.

\section{Study selection process}

Eligibility criteria were applied independently by two authors (TDPC and PRG). Any discrepancies were resolved by consensus with a third author (MAGM). Evaluators were first trained and calibrated for the process of identification and selection of studies, performing several screening rounds (50 papers each). The reliability of the study selection process was estimated calculating inter-agreement scores and Cohen's kappa ( $\kappa)$ values. Articles were selected in two stages: screening titles and abstracts for those apparently meeting inclusion criteria (stage I, $100 \%$ of agreement; $\kappa=1.00$ ), and reading the full-text of previously selected articles, excluding those not meeting eligibility criteria (stage II, $99.70 \%$ of agreement; $\kappa=0.95$ ).

\section{Data extraction}

One author (TDPC) independently extracted data from the selected articles. A standardized full-text analysis was performed using Excel v.16.46 spreadsheets (Microsoft, Redmond, WA, USA). Datasets were crosschecked by a second author (PRG). All discrepancies were also solved by consensus. Data were gathered on the first, last, and corresponding author; publication year; country and continent; source of patient recruitment; recruitment and follow-up periods; sample size; absolute and relative frequencies of mental disorders; study design; location and clinical appearance of lesions; diagnostic criteria for OLP; suspicion method for mental disorders; specialists implied; sex; age; and tobacco and alcohol consumption.

\section{Evaluation of quality and risk of bias of primary-level studies}

Two authors (TDPC and PRG) evaluated the quality and risk of using a specific method for systematic reviews addressing prevalence questions (Joanna Briggs Institute, University of Adelaide, Australia) [23]. The following items were critically appraised: (1) Was the sample representative of the target population?; (2) Were study participants recruited in an appropriate way?; (3) Was the sample size adequate?; (4) Were the study subjects and the setting described in detail?; (5) Was the data analysis conducted with sufficient coverage of the identified sample?; (6) Were objective, standard criteria used for the measurement of the condition?; (7) Was the condition measured reliably?; (8) Was the statistical analysis appropriate?; (9) Were all important confounding factors/subgroups/differences identified and accounted for?; (10) Were subpopulations identified using objective criteria?. Each domain was categorized as "Yes" (low RoB), "Unclear" (moderate RoB), and "No" (High RoB). Furthermore, a specific score was attributed to individual items (low $\mathrm{RoB}=3$; moderate $\mathrm{RoB}=2$; high $\mathrm{RoB}=1$ ) to obtain an overall RoB estimate.

\section{Statistical analysis}

The prevalence of mental disorders among patients with OLP was calculated extracting the raw numerators (number of cases with depression, anxiety, and stress) and denominators (patients with OLP). These proportions and their corresponding $95 \%$ confidence intervals $(95 \% \mathrm{CI})$, constructed using the score method [24], were meta-analyzed to obtain pooled proportions (PP) expressed as percentage. The influence of studies with extreme values $(0,100$, or close to 0 or 100) was minimized by using Freeman-Tukey double-arcsine transformation, to stabilize the variance of the study-specific prevalence [25]. The magnitude of association between OLP and mental disorders (i.e., depression, anxiety, and stress) was also separately explored estimating and combining odds ratios (OR) with 95\% CI. All meta-analyses were performed using random-effects models, weighed by the inverse-variance based on the DerSimonian and Laird method [26], to account for the possibility that there are different underlying results among study subpopulations (e.g., differences in geographic areas, sex, age, suspicion method, etc.). Forest plots were constructed to graphically represent the overall 
effect and for subsequent visual inspection analyses $(p<0.05$ was considered significant).

Heterogeneity between studies was assessed applying the $\chi^{2}$-based Cochran's $\mathrm{Q}$ test (given its low statistical power, $p<0.10$ was considered significant). $I^{2}$ statistic was also quantified (values of $50-75 \%$ were interpreted as moderateto-high degree of inconsistency across the studies) to estimate what proportion of the variance in observed effects reflects variation in true effects, rather than sampling error $[27,28]$. Preplanned stratified meta-analyses were performed to identify potential sources of heterogeneity and to determine subgroups-specific prevalence [29]. The potential effect of study covariates on the prevalence of mental disorders in OLP was also explored using meta-regression [30]. We performed univariable and multivariable random-effects meta-regression analyses using the restricted maximum likelihood (REML) method [31]. The covariates identified to be statistically significant $(p<0.05)$ in a first-step univariable analysis were included in a multivariable meta-regression model. Considering the low number of studies with data available for some meta-regression analyses, the $p$ values were calculated using a permutation test based on Monte Carlo simulations (1,000 permutations) [32]. Weighted bubble plots were also constructed to graphically represent the fitted meta-regression lines.

Finally, secondary analyses were carried out to test the stability and reliability of meta-analysis results. Therefore, sensitivity analyses were carried out to explore the influence individual primary-level studies on the pooled estimates [33]. For this, the meta-analyses were repeated sequentially, omitting one study at a time ("leave-one-out" method). Furthermore, funnel plots were constructed to evaluate smallstudy effects, such as publication bias [34]. In addition, the Egger [35] regression test was applied performing a linear regression of the effect estimates on their standard errors, weighting by $1 /$ (variance of the effect estimate), considering a $p_{\text {Egger }}$ value of $<0.10$ as significant. In addition, trying to confirm the absence of small-study effects, a nonparametric "trim and fill" method was used to identify and potentially correct the funnel plot asymmetry [36]. The statistical analysis was designed by PRG and executed by TDPC, using Stata software (version 16.1, Stata Corp, USA).

\section{Validation of methodological quality}

Two independent authors (PRG and TDPC) critically designed and validated the methodology followed in this systematic review and meta-analysis using AMSTAR2 tool [19], created as an instrument to develop, evaluate, and validate high-quality systematic reviews through 16 items (the 16-item checklist is listed in the Appendix, pp. 62-65). An overall rating is obtained based on weaknesses in critical domains (i.e., items $2,4,7,9,11,13$, and 15) and noncritical domains. The overall confidence on the methodology of the systematic review is rated in one of the four levels: "High," "Moderate," "Low," and "Critically low" (the full explanation is also listed in the Appendix, p. 66).

\section{Results}

\section{Literature search}

The flow diagram (Fig. 1) illustrates the results of the study selection process. We identified a total of 12,917 records published before January 2021 (Appendix Table 1, p. 5): 3,578 from PubMed, 3,227 from Embase, 2,931 from Web of Science, 3,171 from Scopus, 10 from PsycInfo, and 3 from handsearching methods ( 2 from the bibliographic reference lists [37, 38] and one from Google Scholar [6]). After removal of duplicate records, 4,925 were potentially eligible. Once the titles and abstracts had been screened, 1,670 studies were evaluated in full-text, of which 1,445 studies did not comply with the inclusion criteria. Finally, 51 studies were included in the qualitative and quantitative analysis (references for included and excluded studies-with their reasons for exclusion reasons-are listed in the Appendix, pp. 69-73).

\section{Study characteristics}

Table 1 summarizes the general characteristics of the 51 meta-analyzed studies, which recruited 6,815 patients. Supplementary Table 2 displays in more detail the characteristics and variables collected (Appendix Table 2, pp. 6-8).

Thirty-three studies (4,031 patients) reported data on the prevalence of depression in OLP patients. Regarding the prevalence by continents, 10 studies (441 patients) took place in Asia, 16 (2,902 patients) in Europe, 3 (170 patients) in North America, 3 (148 patients) in South America, and only one multicentric across various continents. Besides, prevalence by depression suspicion method was also performed: 6 studies (503 patients) diagnosed this disorder using hospital and anxiety depression scale (HADS), 5 studies (163 patients) by depression, anxiety and stress scale-21 items (DASS-21), 4 studies (948 patients) by anamnesis, 4 studies (670 patients) by Hamilton Depression Rating Scale (HAM-D), 2 studies (161 patients) by Beck depression inventory II (BDI-II), 1 study (100 patients) by Zung Self-Rating Depression Scale (SDS), and another study (91 patients) by Center for Epidemiological Studies-Depression Scale (CES-D). However, 8 studies (1,280 patients) did not describe how the suspicion was made and 2 studies (115 patients) used multiple tests. Depression was diagnosed in collaboration with a psychologist in 2 studies (161 patients), with a psychiatrist in 3 studies (169 patients), and with the 


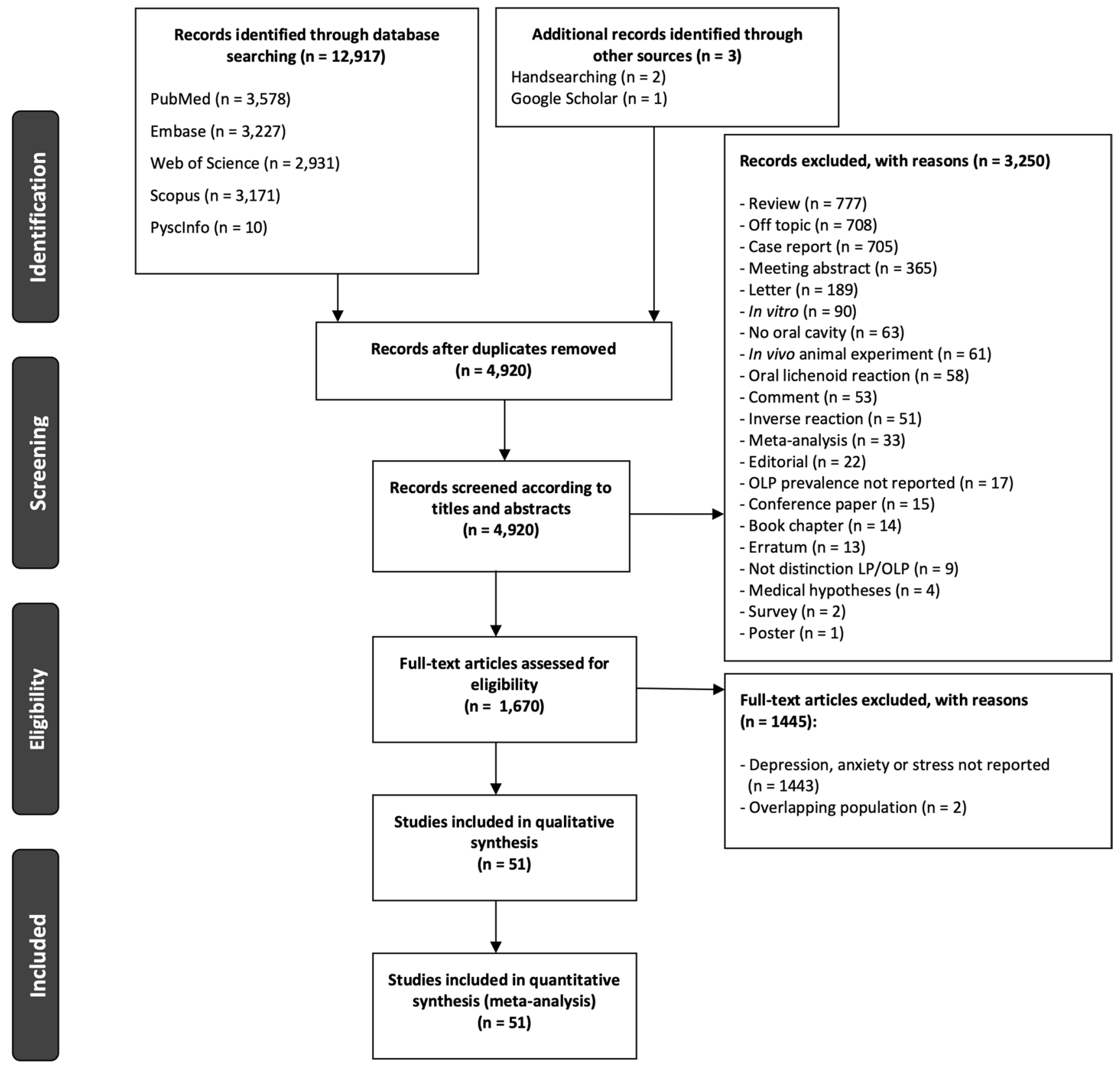

Fig. 1 Flow diagram showing the identification and selection process of studies that address the prevalence of psychological disorders among OLP patients

rest of specialists-including dentists, dermatologists, and/or oral medicine/pathologists—in 28 studies $(3,701$ patients).

Thirty-one studies (3,336 patients) reported data on the prevalence of anxiety in OLP patients. With regard to the prevalence by continents, 9 studies (535 patients) took place in Asia, 16 (2,236 patients) in Europe, 1 (10 patients) in North America, 4 (185 patients) in South America, and only one multicentric across various continents. In addition, prevalence by anxiety suspicion method was also performed: 6 studies (348 patients) by State-Trait
Anxiety Inventory (STAI), 5 (703 patients) by Hamilton Anxiety Rating Scale (HAM-A), another 5 (458 patients) by HADS, and further 5 (163 patients) by DASS-21 test. Moreover, 2 studies (117 studies) diagnosed this disorder by anamnesis and 2 more (274 patients) by Zung SelfRating Anxiety Scale (SAS). However, 4 studies $(1,101$ patients) did not describe how the suspicion was made and one study (45 patients) used multiple tests. Anxiety was diagnosed in collaboration with a psychologist in 2 studies (161 patients), by a psychiatrist in another 2 studies (102 patients), and by the rest of specialists-including dentists, 
Table 1 Characteristics of the studies included in the meta-analysis

\begin{tabular}{|c|c|c|c|c|}
\hline & All studies & Depression & Anxiety & Stress \\
\hline Total studies & 51 studies & 33 studies & 31 studies & 24 studies \\
\hline \multicolumn{5}{|l|}{ Sample size } \\
\hline Total no. of patients & 6,815 & 4,031 & 3,336 & 3,450 \\
\hline Range & $9-803$ & $9-803$ & $9-600$ & $9-723$ \\
\hline Publication year & 1992-2021 & $1995-2021$ & $1993-2021$ & 1992-2020 \\
\hline \multicolumn{5}{|l|}{ Geographic area } \\
\hline Asia & 15 studies ( 4 countries) & 10 studies ( 3 countries) & 9 studies ( 2 countries) & 9 studies ( 2 countries) \\
\hline Europe & 25 studies (13 countries) & 16 studies (10 countries) & 16 studies ( 9 countries) & 9 studies ( 8 countries) \\
\hline North America & 4 studies ( 1 country) & 3 studies ( 1 country) & 1 studies ( 1 country) & 2 studies ( 1 country) \\
\hline South America & 5 studies ( 2 countries) & 3 studies ( 2 countries) & 4 studies ( 2 countries) & 2 studies ( 2 countries) \\
\hline Global & 2 studies ( 2 countries) & 1 studies ( 1 country) & 1 studies ( 1 country) & 2 studies ( 2 countries) \\
\hline Total & 3 continents ( 22 countries) & 3 continents ( 17 countries) & 3 continents ( 15 countries) & 3 continents ( 15 countries) \\
\hline \multicolumn{5}{|c|}{ Specialist implied in diagnosis } \\
\hline Psychologist & 2 studies (161 patients) & 2 studies (161 patients) & 2 studies (161 patients) & 2 studies (161 patients) \\
\hline Psychiatrist & 3 studies (169 patients) & 3 studies (169 patients) & 2 studies (102 patients) & - \\
\hline $\begin{array}{l}\text { Oral medicine-patholo- } \\
\text { gist/dentist/dermatolo- } \\
\text { gist }\end{array}$ & 46 studies ( 6,485 patients) & 28 studies ( 3,701 patients $)$ & 27 studies (3,073 patients) & 22 studies (3,289 patients) \\
\hline \multicolumn{5}{|l|}{ Suspicion methods } \\
\hline Anamnesis & 8 studies (1,551 patients) & 4 studies (948 patients) & 2 studies (117 patients) & 4 studies (558 patients) \\
\hline BDI-II & 2 studies (161 patients) & 2 studies (161 patients) & - & $\longrightarrow$ \\
\hline CES-D & 1 study (91 patients) & 1 study (91 patients) & - & - \\
\hline DASS-21 & 5 studies (163 patients) & 5 studies (163 patients) & 5 studies (163 patients) & 5 studies (163 patients) \\
\hline HADS & 6 studies (503 patients) & 6 studies (503 patients) & 5 studies (458 patients) & 1 study (49 patients) \\
\hline HAM-A & 5 studies (703 patients) & - & 5 studies (703 patients) & - \\
\hline HAM-D & 4 studies (670 patients) & 4 studies (670 patients) & - & - \\
\hline PGWBI & 1 study (67 patients) & $\longrightarrow$ & 1 study (67 patients) & $\longrightarrow$ \\
\hline PSQ & 1 study (49 patients) & - & $\longrightarrow$ & 1 study (49 patients) \\
\hline PSS-10 & 2 studies (302 patients) & - & $\longrightarrow$ & 2 studies (302 patients) \\
\hline SAS & 2 studies (274 patients) & - & 2 studies (274 patients) & - \\
\hline SDS & 6 studies (348 patients) & 1 study (100 patients) & - & - \\
\hline STAI & 6 studies (348 patients) & - & 6 studies (348 patients) & - \\
\hline Test of recent experience & 1 study (9 patients) & - & - & 1 study (9 patients) \\
\hline WCQ & 1 study (112 patients) & - & - & 1 study (112 patients) \\
\hline Multiple & 3 studies (160 patients) & 2 studies (115 patients) & 1 study (45 patients) & - \\
\hline Not described & 16 studies (3,118 patients) & 8 studies (1,280 patients) & 4 studies (1,101 patients) & 9 studies (2,208 patients) \\
\hline
\end{tabular}

dermatologists, and/or oral medicine/pathologists—in 27 studies (3,073 patients).

Twenty-four studies $(3,450$ patients) reported data on the prevalence of stress in OLP patients. Regarding the prevalence by continents, 9 studies (527 patients) took place in Asia, another 9 (1,691 patients) in Europe, 2 (768 patients) in North America, further 2 (30 patients) in South America, and two multicentric across various continents. Moreover, prevalence by stress suspicion method was also performed: 5 studies (163 patients) by DASS-21 test, 4 (558 patients) by anamnesis, 2 (302 patients) by Perceived Stress Scale (PSS10) and Ways of Coping Questionnaire (WCQ), HADS,
General Perceived Stress Questionnaire (PSQ), and Test of Recent Experience were used in one study (112, 49, 49 and 9 patients) respectively. Stress was diagnosed in collaboration with a psychologist in 2 studies (161 patients) and by the rest of specialists-including dentists, dermatologists, and/or oral medicine/pathologists_-in 22 studies (3,289 patients).

\section{Qualitative analysis}

According to our risk of bias (RoB) analysis, all the studies were not conducted with the same scrupulousness, being the items Q2, Q9, and Q10, and those with the highest risk of 
bias (Fig. 2). The Q2 item investigates whether the studies recruited patients adequately, not reporting most of them random sampling methods from the study population. The Q9 item targets biases due to the lack of control of potentially confounding factors in the studies (design, measurement, and/or communication). The Q10 item assesses whether the relevant data from the study subpopulations (sex, age, alcohol and tobacco consumption) were reported appropriately.

\section{Quantitative analysis (meta-analysis)}

The results of the meta-analyses were graphically depicted in forest plots (Fig. 3, Appendix) and detailed in Table 2.

\section{Depression}

\section{Prevalence of depression in OLP patients}

The pooled proportion (PP) was 31.19\% (95\% $\mathrm{CI}=22.27-40.82$ ), with a high degree of heterogeneity $\left(I^{2}=97.14 \%, p<0.001\right)$ (Fig. 3).

\section{Magnitude of association between depression and OLP}

Patients with OLP showed a significantly higher frequency of depression than the general population control group $(\mathrm{OR}=6.15,95 \% \mathrm{CI}=2.72-13.89, p<0.001$; Appendix p. 9).

\section{Subgroup meta-analyses and meta-regressions}

In the stratified analyses (Appendix pp. 10-14), we found significant differences between continents $(p<0.001)$, finding the highest prevalence in South America $(\mathrm{PP}=55.58 \%$, 95\% CI $=47.20-63.81)$ and Asia $(\mathrm{PP}=43.35 \%, 95 \%$ $\mathrm{CI}=22.91-64.97)$. We also observed significant results between the tests used to diagnose depression. After adjustment in a multivariable meta-regression model, only anxiety maintained the statistical significance $(p=0.02)$, probably being the most influential covariate associated with the OLP depression comorbidity (Table 2; Fig. 4).

\section{Anxiety}

\section{Prevalence of anxiety in OLP patients}

The estimated PP was 54.76\% (95\% CI $=42.06-67.17)$, with a high degree of heterogeneity $\left(I^{2}=98.00 \%, p<0.001\right)$ (Fig. 3).

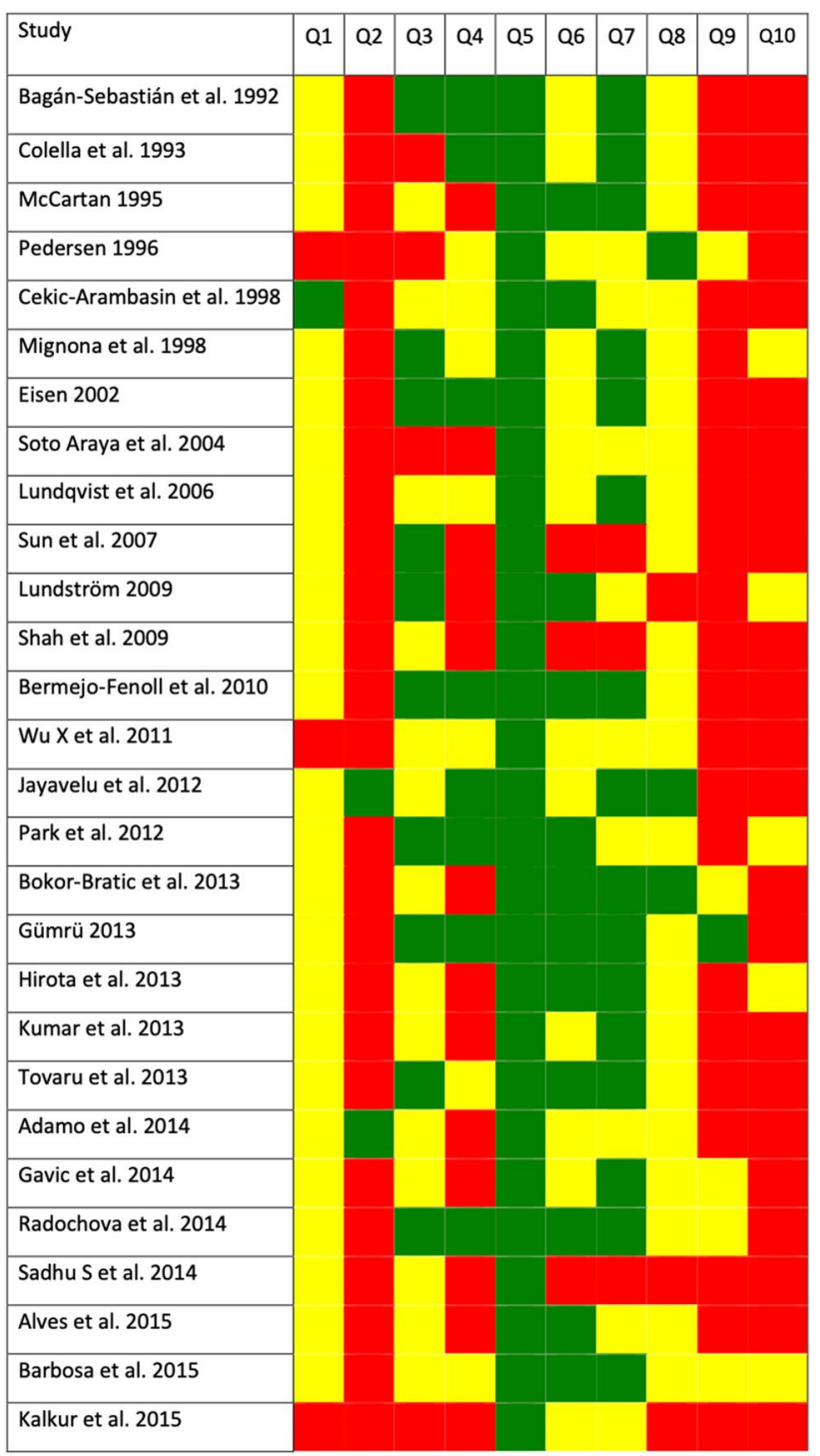

Fig. 2 Quality plot graphically representing the risk of bias in individual studies, critically appraising ten domains, using a method specifically designed for systematic reviews addressing questions of prevalence (developed by the Joanna Briggs Institute, University of Adelaide, South Australia). Green, low risk of potential bias; yellow, moderate; red, high

\section{Magnitude of association between anxiety and OLP}

Patients with OLP showed a significantly higher frequency of anxiety than the general population control group $(\mathrm{OR}=3.51,95 \% \mathrm{CI}=2.10-5.85, p<0.001$; Appendix p. 25$)$.

\section{Subgroup meta-analyses and meta-regressions}

In the subgroup analyses (Appendix pp. 26-30), we found significant differences between continents $(p<0.001)$; South America outnumbered the rest of continents with the highest prevalence ( $\mathrm{PP}=99.88 \%, 95 \% \mathrm{CI}=95.71-100.00)$. 
Table 2 Prevalence and magnitude of association of depression in patients with OLP and associated factors

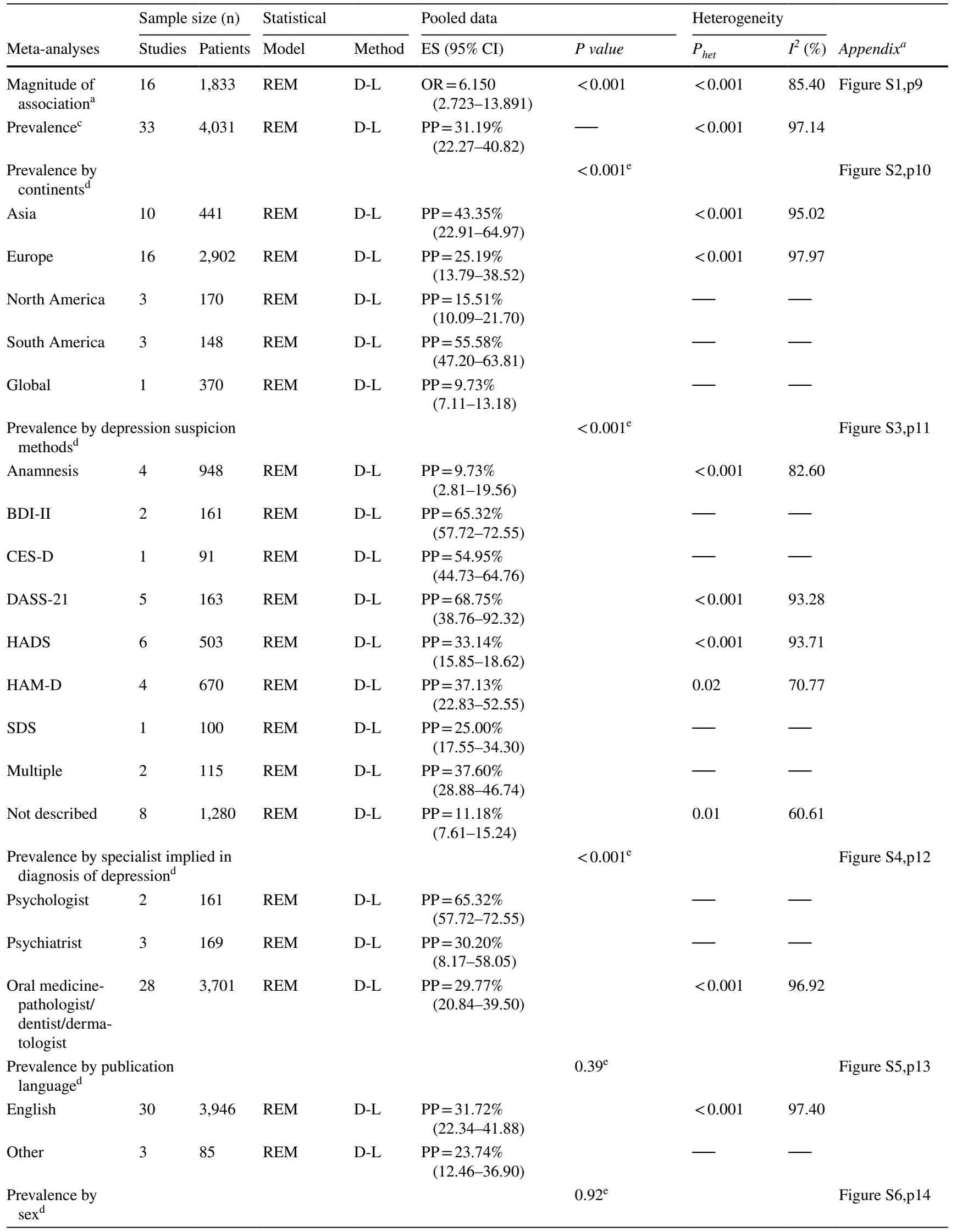


Table 2 (continued)

\begin{tabular}{|c|c|c|c|c|c|c|c|c|c|}
\hline \multirow[b]{2}{*}{ Meta-analyses } & \multicolumn{2}{|c|}{ Sample size (n) } & \multicolumn{2}{|c|}{ Statistical } & \multicolumn{2}{|l|}{ Pooled data } & \multicolumn{2}{|c|}{ Heterogeneity } & \multirow[b]{2}{*}{ Appendix ${ }^{a}$} \\
\hline & Studies & Patients & Model & Method & ES $(95 \% \mathrm{CI})$ & $P$ value & $P_{\text {het }}$ & $I^{2}(\%)$ & \\
\hline Females & 9 & 1,122 & REM & D-L & $\begin{array}{l}\mathrm{PP}=18.96 \%(4.96- \\
37.93)\end{array}$ & & $<0.001$ & 93.79 & \\
\hline Males & 9 & 1,122 & REM & D-L & $\begin{array}{l}\mathrm{PP}=14.32 \%(0.00- \\
41.75)\end{array}$ & & 0.06 & 86.27 & \\
\hline \multicolumn{10}{|c|}{$\begin{array}{l}\text { Prevalence. Univariable } \\
\text { meta-regression }\end{array}$} \\
\hline $\begin{array}{l}\text { Sex (\% OLP } \\
\text { females })\end{array}$ & 32 & 4,006 & \multicolumn{2}{|c|}{$\begin{array}{l}\text { Random-effects meta- } \\
\text { regression }\end{array}$} & $\begin{array}{l}\text { Coef }=-0.0029 \\
\quad(-0.0109 \text { to } 0.0050)\end{array}$ & $0.47 \pm 0.016^{\mathrm{g}}$ & \multicolumn{2}{|c|}{ het $_{\text {explained }}=-2.52 \%^{\mathrm{h}}$} & Figure S7,p.15 \\
\hline $\begin{array}{l}\text { Age (mean age of } \\
\text { OLP patients) }\end{array}$ & 31 & 3,967 & \multicolumn{2}{|c|}{$\begin{array}{l}\text { Random-effects meta- } \\
\text { regression }\end{array}$} & $\begin{array}{l}\text { Coef }=-0.0133 \\
\quad(-0.0275 \text { to } 0.0009)\end{array}$ & $0.07 \pm 0.009^{g}$ & \multicolumn{2}{|c|}{ het $_{\text {explained }}=7.59 \%^{\mathrm{h}}$} & Figure S8,p.16 \\
\hline $\begin{array}{l}\text { Tobacco (\% OLP } \\
\text { smokers) }\end{array}$ & 12 & 2,534 & \multicolumn{2}{|c|}{$\begin{array}{l}\text { Random-effects meta- } \\
\text { regression }\end{array}$} & $\begin{array}{l}\text { Coef }=0.0025 \\
\quad(-0.0123 \text { to } 0.0174)\end{array}$ & $0.74 \pm 0.014^{\mathrm{g}}$ & \multicolumn{2}{|c|}{ het $\mathrm{explained}=-9.56 \%^{\mathrm{h}}$} & Figure S9,p.17 \\
\hline $\begin{array}{l}\text { Alcohol (\% OLP } \\
\text { drinkers) }\end{array}$ & 6 & 1,447 & \multicolumn{2}{|c|}{$\begin{array}{l}\text { Random-effects meta- } \\
\text { regression }\end{array}$} & $\begin{array}{l}\text { Coef }=-0.0045 \\
\quad(-0.0211 \text { to } 0.0120)\end{array}$ & $0.43 \pm 0.016^{\mathrm{g}}$ & \multicolumn{2}{|c|}{$\begin{array}{l}\text { het- } \\
\text { explained }=-13.92 \%^{\mathrm{h}}\end{array}$} & Figure S10, p.18 \\
\hline $\begin{array}{l}\text { Red lesions } \\
\quad \text { (\%OLP patients) }\end{array}$ & 17 & 2,074 & \multicolumn{2}{|c|}{$\begin{array}{l}\text { Random-effects meta- } \\
\text { regression }\end{array}$} & $\begin{array}{l}\text { Coef }=-0.0019 \\
(-0.0057 \text { to } 0.0019)\end{array}$ & $0.30 \pm 0.015^{\mathrm{g}}$ & \multicolumn{2}{|c|}{ het $\mathrm{explained}=-0.59 \%^{\mathrm{h}}$} & Figure S11, p.19 \\
\hline Anxiety & 25 & 2,924 & \multicolumn{2}{|c|}{$\begin{array}{l}\text { Random-effects meta- } \\
\text { regression }\end{array}$} & $\begin{array}{l}\text { Coef }=0.0065 \\
(0.0040 \text { to } 0.0089)\end{array}$ & $<0.001^{\mathrm{g}}$ & \multicolumn{2}{|c|}{ het $\mathrm{explained}=75.25 \% \mathrm{~h}$} & Figure S12, p.20 \\
\hline Stress & 13 & 1,671 & \multicolumn{2}{|c|}{$\begin{array}{l}\text { Random-effects meta- } \\
\text { regression }\end{array}$} & $\begin{array}{l}\text { Coef }=0.0069 \\
(0.0000 \text { to } 0.0138)\end{array}$ & $0.05 \pm 0.008^{g}$ & \multicolumn{2}{|c|}{ het $\mathrm{explained}=34.82 \%^{\mathrm{h}}$} & Figure $S 13$, p. 21 \\
\hline Year & 33 & 4,031 & \multicolumn{2}{|c|}{$\begin{array}{l}\text { Random-effects meta- } \\
\text { regression }\end{array}$} & $\begin{array}{l}\text { Coef }=0.0122 \\
\quad(-0.0055 \text { to } 0.0300)\end{array}$ & $0.13 \pm 0.011^{\mathrm{g}}$ & \multicolumn{2}{|c|}{ het $_{\text {explained }}=7.17 \% \mathrm{~h}$} & Figure S14, p.22 \\
\hline HDI & 33 & 4,031 & \multicolumn{2}{|c|}{$\begin{array}{l}\text { Random-effects meta- } \\
\text { regression }\end{array}$} & $\begin{array}{c}\text { Coef }=-1.4243 \\
(-0.2 .2701 \text { to } \\
-0.2 .2701)\end{array}$ & $0.004 \pm 0.002^{g}$ & \multicolumn{2}{|c|}{ het $_{\text {explained }}=33.02 \%^{\mathrm{h}}$} & Figure S15, p.23 \\
\hline RoB & 33 & 4,031 & \multirow{2}{*}{\multicolumn{2}{|c|}{$\begin{array}{l}\text { Random-effects meta- } \\
\text { regression }\end{array}$}} & $\begin{array}{l}\text { Coef }=-0.1759 \\
\quad(-0.5084 \text { to } 0.1565)\end{array}$ & $0.32 \pm 0.015^{\mathrm{g}}$ & \multirow{2}{*}{\multicolumn{2}{|c|}{ het $_{\text {explained }}=2.65 \%^{\mathrm{h}}$}} & Figure S16,p.24 \\
\hline \multicolumn{6}{|c|}{$\begin{array}{l}\text { Prevalence. Multivariable } \\
\text { meta-regression }^{\mathrm{f}}\end{array}$} & & & & \\
\hline Anxiety & 11 & 1,033 & $\begin{array}{r}\text { Randon } \\
\text { regres }\end{array}$ & ects meta- & $\begin{array}{l}\text { Coef }=0.0107 \\
\quad(0.0025 \text { to } 0.0188)\end{array}$ & $0.02 \pm 0.008^{g}$ & \multirow{3}{*}{\multicolumn{2}{|c|}{ het $_{\text {explained }}=72.59 \%^{\mathrm{h}}$}} & Figure $\mathrm{S} 12, \mathrm{p} .20$ \\
\hline Stress & & & $\begin{array}{l}\text { Randon } \\
\text { regres }\end{array}$ & cts meta- & $\begin{array}{l}\text { Coef }=-0.0006 \\
(-0.0090 \text { to } 0.0079)\end{array}$ & $0.87 \pm 0.002^{\mathrm{g}}$ & & & Figure $S 13, p .21$ \\
\hline HDI & & & $\begin{array}{r}\text { Randon } \\
\text { regres }\end{array}$ & ects meta- & $\begin{array}{l}\text { Coef }=0.0728 \\
\quad(-0.1 .437 \text { to } 1.1470)\end{array}$ & $0.90 \pm 0.001^{\mathrm{g}}$ & & & Figure S15, p.23 \\
\hline
\end{tabular}

Abbreviations: Stat., statistical; Wt, method of weighting; $P P$, pooled proportion; $C I$, confidence intervals; $R E M$, random-effects model; $D-L$, DerSimonian and Laird method; OLP, oral lichen planus; BDI-II, Beck depression inventory II; CES-D, Center for Epidemiological StudiesDepression Scale; DASS-21, depression, anxiety and stress scale-21 items; HADS, hospital and anxiety depression scale; HAM-D, Hamilton Depression Rating Scale; SDS, Zung Self-Rating Depression Scale

${ }^{a}$ Magnitude of association meta-analyses

${ }^{\mathrm{b}}$ More information in the appendix

${ }^{\mathrm{c}}$ Proportion meta-analyses

${ }^{\mathrm{d}}$ Proportion meta-analyses (subgroup analyses)

${ }^{\mathrm{e}}$ Test for between-subgroup differences

${ }^{\mathrm{f}}$ Effect of study covariates on the prevalence of depression, anxiety, or stress among OLP patients. A meta-regression coefficient $>0$ indicates a greater impact of covariates on the prevalence of mental disorders in patients with OLP

${ }^{\mathrm{g}} P$ value \pm standard error after 10,000 permutations based on Monte Carlo simulation

${ }^{\text {h}}$ Proportion of between-study variance explained (adjusted $R^{2}$ statistic) using the residual maximum likelihood (REML) method. A negative number for proportion of heterogeneity explained reflects no heterogeneity explained

${ }^{i}$ Adjusted model for prevalence of depression in OLP (number of comparisons $=11$ ); adjusted $R^{2}$ statistic $=72.59 \%$; joint test for all covariates $F=0.0225, p=0.0107$ 


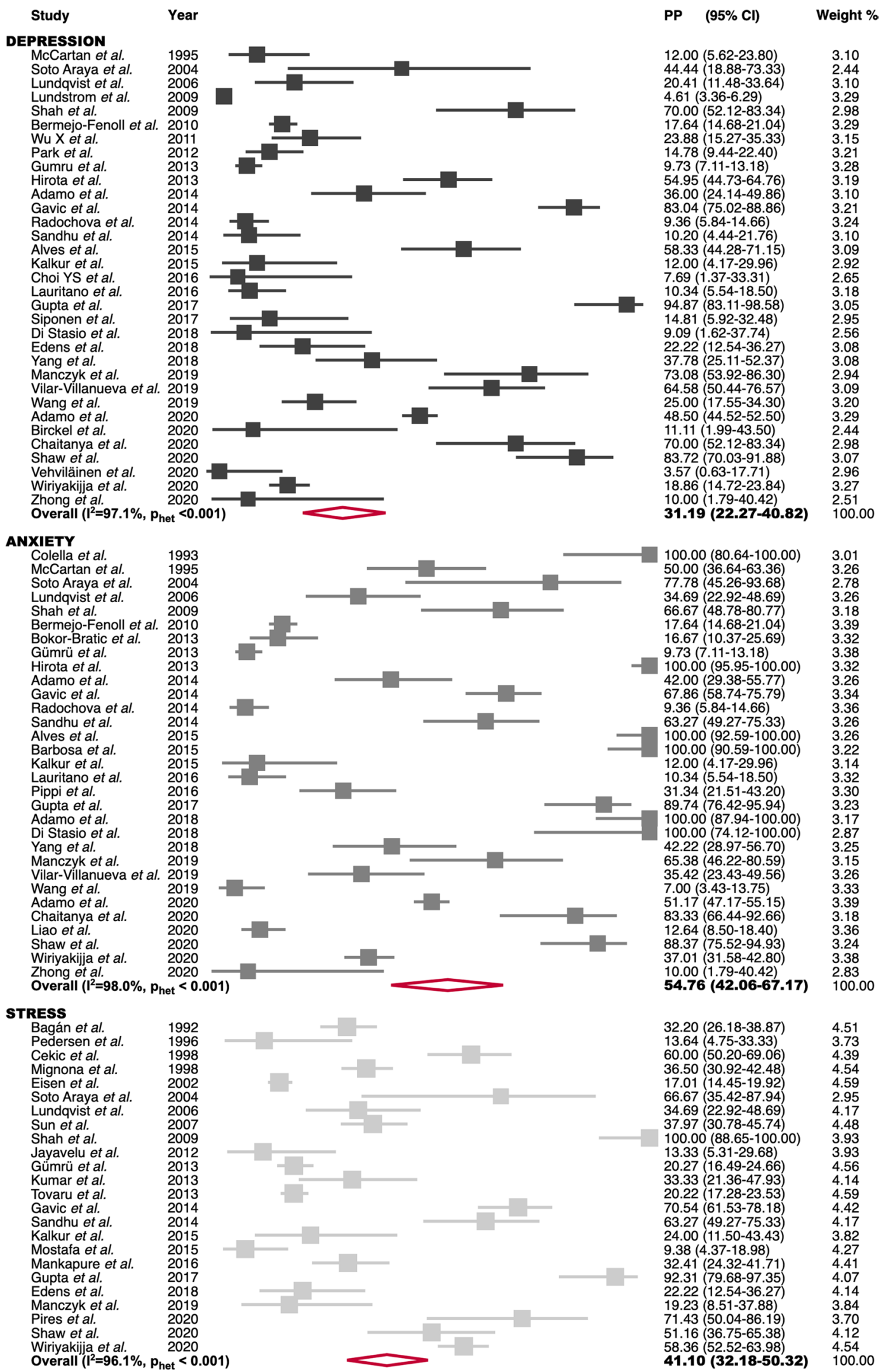

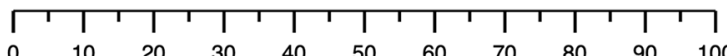
Prevalence of Psychological Disorders among OLP patients (\%) 
४Fig. 3 Forest plot graphically representing the prevalence of depression, anxiety, and stress among OLP patients

Moreover, significant differences were observed between the tests used to diagnose anxiety. The prevalence did not vary significantly for the rest of the factors investigated (age, sex, tobacco and alcohol consumption) in the univariate metaregression analyses (Appendix pp. 31-38) except for HDI $(p=0.03)$ (Table 3).

\section{Stress}

\section{Prevalence of stress in OLP patients}

The PP was $41.10 \%(95 \% \mathrm{CI}=32.18-50.32)$, with a significant degree of heterogeneity $\left(I^{2}=96.11 \%, p<0.001\right)$ (Fig. 3).

\section{Magnitude of association between stress and OLP}

Patients with OLP showed a significantly higher frequency of anxiety than the general population control group $(\mathrm{OR}=3.64,95 \% \mathrm{CI}=1.48-8.94, p=0.005$; Appendix p. 39).

\section{Subgroup meta-analyses and meta-regressions}

In the stratified analyses (Appendix pp. 40-44), we found significant differences between continents $(p<0.001)$, finding the highest prevalence in South America. Prevalence did not vary significantly for the rest of the factors investigated

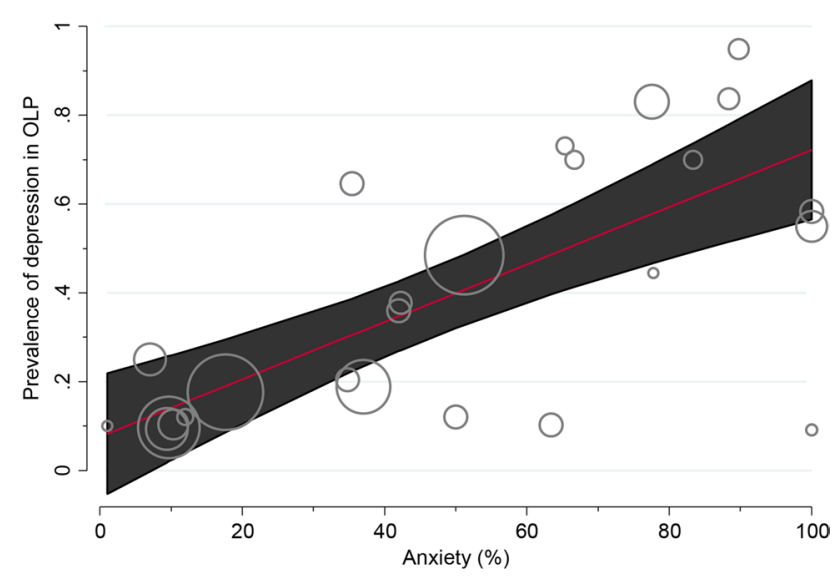

Fig. 4 Bubble plot graphically representing the potential effect of the covariate anxiety (expressed as the percentage of patients with signs of anxiety, in x-axis) on the prevalence of depression among OLP patients (expressed as proportions, in y-axis). The fitted metaregression line (red line) was depicted with their corresponding 95\% confidence intervals (black area), together with bubbles (grey circles) representing the estimates from primary-level studies (sized according to the precision of each estimate, the inverse of its within-study variance, in a z-axis) (age, sex, tobacco, alcohol, and HDI) in the univariate metaregression analyses (Appendix pp. 45-52) (Table 4).

\section{Quantitative evaluation (secondary analyses)}

\section{Sensitivity analysis}

The consecutive repetition of meta-analyses using the "leave-one-out" method (Appendix, pp. 56-61) did not vary the overall results considerably. Hence, the reported pooled estimations are not influenced by a specific primary-level study.

\section{Analysis of small-study effects}

Egger's regression test indicated statistically significant asymmetry for the prevalence of depression, anxiety, and stress in OLP patients ( $p_{\text {Egger }}=0.09,0.01$, and 0.02 , respectively). Funnel plots (Appendix pp. 53-55) appeared to be slightly asymmetric for the studies plotted at the bottom, singularly for anxiety variable; however, due to a considerable degree of inter-study heterogeneity, the visual inspection analysis was complex. Nevertheless, the nonparametric trim and fill method did not detect the presence of unpublished studies, so the final estimates were not adjusted based on imputation techniques for missing studies. In summary, the presence of small-study effects was suspected, but publication bias was potentially ruled out.

\section{Validation of methodological quality}

The methods applied in this systematic review and metaanalysis were implemented, critically appraised, and validated using AMSTAR2 [39], obtaining an overall rating of "high" (15 out of 16 points) (the checklist, explanation, and scoring table are included in the Appendix, pp. 62-66).

\section{Discussion}

The results of our systematic review and meta-analysis show a strong association between OLP and psychological disorders, i.e., depression, anxiety, and stress. Patients with OLP present a risk of suffering from depression $(p<0.001)$, anxiety $(p<0.001)$, and stress $(p<0.005)$ significantly higher than the general population, with a prevalence of depression of $31.19 \%$, anxiety of $54.76 \%$, and stress of $41.10 \%$ among OLP patients. Our results were derived from the analysis of 51 studies that collected information from 6,815 patients with OLP. A meta-analysis on the subject that included patients with OLP [12] has recently been published, reporting a prevalence of depression and anxiety of $26 \%$ and $27 \%$ of the cases, respectively. It must be noted that this 
Table 3 Prevalence and magnitude of association of anxiety in patients with OLP and associated factors

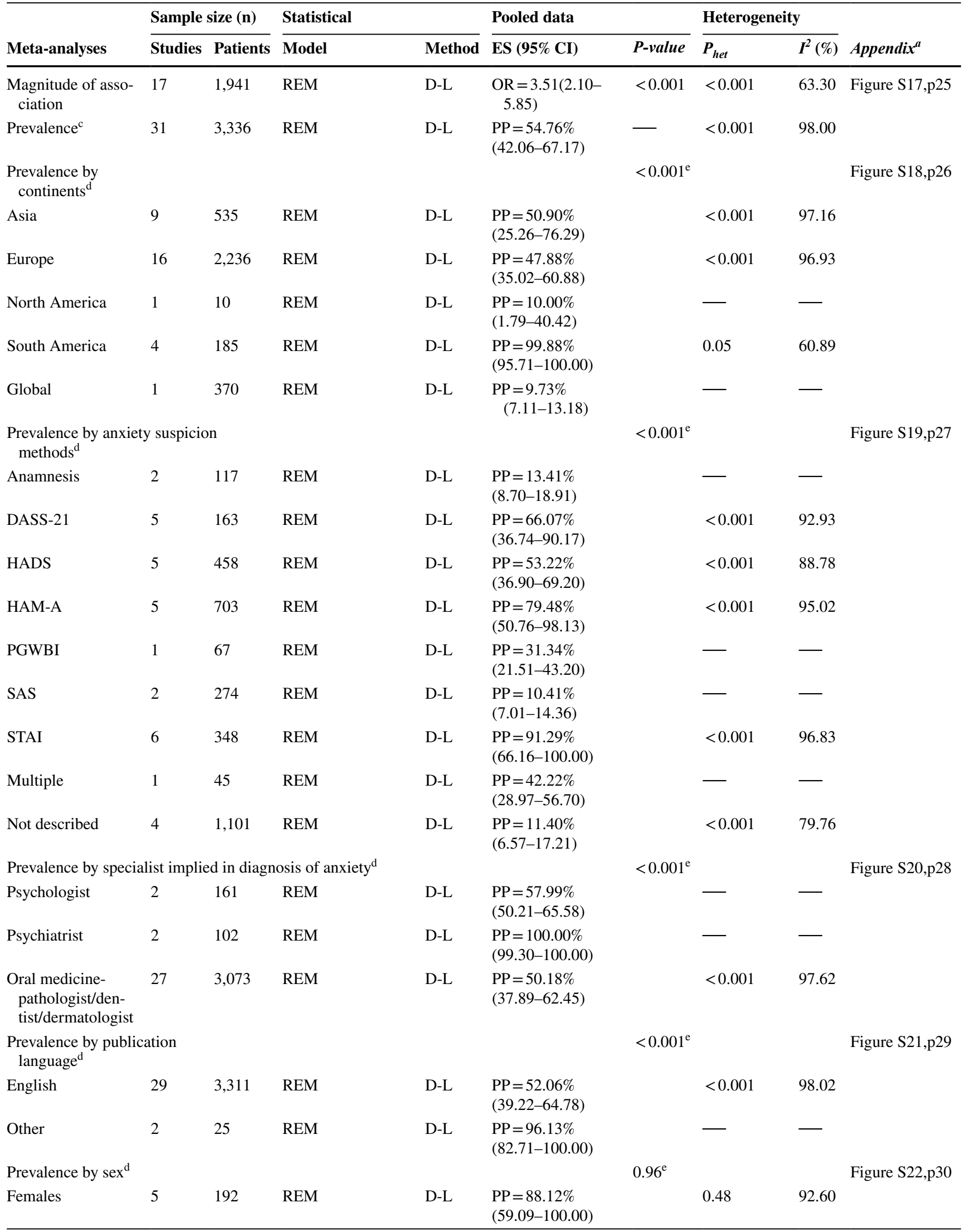


Table 3 (continued)

\begin{tabular}{|c|c|c|c|c|c|c|c|c|}
\hline \multirow[b]{2}{*}{ Meta-analyses } & \multicolumn{2}{|c|}{ Sample size (n) } & Statistical & \multicolumn{2}{|l|}{ Pooled data } & \multicolumn{2}{|c|}{ Heterogeneity } & \multirow[b]{2}{*}{ Appendix ${ }^{a}$} \\
\hline & Studies & Patients & Method & ES $(95 \%$ CI $)$ & P-value & $P_{h e t}$ & $I^{2}(\%)$ & \\
\hline Males & 5 & 192 & REM & $\begin{array}{l}\mathrm{PP}=93.29 \% \\
(59.37-100.00)\end{array}$ & & 0.37 & 76.08 & \\
\hline \multicolumn{9}{|c|}{$\begin{array}{l}\text { Prevalence. Univariable } \\
\text { meta-regression. }{ }^{\mathrm{f}}\end{array}$} \\
\hline $\begin{array}{l}\text { Sex (\% OLP } \\
\text { females) }\end{array}$ & 30 & 3,311 & $\begin{array}{l}\text { random-effects meta-regres- } \\
\text { sion }\end{array}$ & $\begin{array}{l}\text { Coef }=-.0006 \\
(-.0130 \text { to } .0118)\end{array}$ & $\begin{array}{l}0.92 \pm \\
0.008^{g}\end{array}$ & $\begin{array}{l}\text { het }_{\text {explained }}= \\
-3.92 \%^{\mathrm{h}}\end{array}$ & & Figure $S 23$, p.31 \\
\hline $\begin{array}{l}\text { Age (mean age of } \\
\text { OLP patients) }\end{array}$ & 29 & 3,272 & $\begin{array}{l}\text { random-effects meta-regres- } \\
\text { sion }\end{array}$ & $\begin{array}{l}\text { Coef }=-.0028 \\
(-.0224 \text { to } .0168)\end{array}$ & $\begin{array}{l}0.77 \pm \\
0.013^{\mathrm{g}}\end{array}$ & $\begin{array}{l}\text { het }_{\text {explained }}= \\
-3.93 \%^{\mathrm{h}}\end{array}$ & & Figure $S 24$, p.32 \\
\hline $\begin{array}{l}\text { Tobacco (\% OLP } \\
\text { smokers) }\end{array}$ & 10 & 1,803 & $\begin{array}{l}\text { random-effects meta-regres- } \\
\text { sion }\end{array}$ & $\begin{array}{l}\text { Coef }=-.0020 \\
(-.0132 \text { to } .0093)\end{array}$ & $\begin{array}{l}0.70 \pm \\
0.015^{\mathrm{g}}\end{array}$ & $\begin{array}{l}\text { het }_{\text {explained }}= \\
-13.86 \%{ }^{\mathrm{h}}\end{array}$ & & Figure S25, p.33 \\
\hline $\begin{array}{l}\text { Alcohol (\% OLP } \\
\text { drinkers) }\end{array}$ & 7 & 1,520 & $\begin{array}{l}\text { random-effects meta-regres- } \\
\text { sion }\end{array}$ & $\begin{array}{l}\text { Coef }=-.0003 \\
(-.0125 \text { to } .0120)\end{array}$ & $\begin{array}{l}0.98 \pm \\
0.004^{g}\end{array}$ & $\begin{array}{l}\text { het }_{\text {explained }}= \\
-25.77 \% \mathrm{~h}^{\mathrm{h}}\end{array}$ & & Figure S26, p.34 \\
\hline $\begin{array}{l}\text { Red lesions (\%OLP } \\
\text { patients) }\end{array}$ & 17 & 2,162 & $\begin{array}{l}\text { random-effects meta-regres- } \\
\text { sion }\end{array}$ & $\begin{array}{l}\text { Coef }=-.0015 \\
(-.0079 \text { to } .0049)\end{array}$ & $\begin{array}{l}0.68 \pm \\
0.015^{\mathrm{g}}\end{array}$ & $\begin{array}{l}\text { het }_{\text {explained }}= \\
-6.66 \%{ }^{\mathrm{h}}\end{array}$ & & Figure S27, p.35 \\
\hline Year & 31 & 3,336 & $\begin{array}{l}\text { random-effects meta-regres- } \\
\text { sion }\end{array}$ & $\begin{array}{l}\text { Coef }=-.0060 \\
(-.0258 \text { to } .0137)\end{array}$ & $\begin{array}{l}0.62 \pm \\
0.015^{\mathrm{g}}\end{array}$ & $\begin{array}{l}\text { het }_{\text {explained }}= \\
-2.98 \%{ }^{\mathrm{h}}\end{array}$ & & Figure S28, p.36 \\
\hline HDI & 31 & 3,336 & $\begin{array}{l}\text { random-effects meta-regres- } \\
\text { sion }\end{array}$ & $\begin{array}{l}\text { Coef }=-1.2944 \\
(-2.4707 \text { to }-.1180)\end{array}$ & $\begin{array}{l}0.03 \pm \\
0.006^{\mathrm{g}}\end{array}$ & $\begin{array}{l}\text { het }_{\text {explained }}= \\
18.00 \%{ }^{\mathrm{h}}\end{array}$ & & Figure S29, p.37 \\
\hline RoB & 31 & 3,336 & $\begin{array}{l}\text { random-effects meta-regres- } \\
\text { sion }\end{array}$ & $\begin{array}{l}\text { Coef }=-.3563 \\
(-.7738 \text { to } .0611)\end{array}$ & $\begin{array}{l}0.09 \pm \\
0.009^{g}\end{array}$ & $\begin{array}{l}\text { het } \\
9.31 \%^{\mathrm{h}}\end{array}$ & & Figure S30, p.38 \\
\hline
\end{tabular}

Abbreviations: Stat., statistical; Wt, method of weighting; $P P$, pooled proportion; $C I$, confidence intervals; REM, random-effects model; $D$ - $L$, DerSimonian and Laird method; $O L P$, oral lichen planus; DASS-21, depression, anxiety and stress scale-21 items; HADS, hospital and anxiety depression scale; RoB, Risk of Bias; HAM-A, Hamilton Anxiety Rating Scale; PGWBI, Psychologial General Well-Being Index; SAS, Zung SelfRating Anxiety Scale; STAI, State-Trait Anxiety Inventory

${ }^{a}$ Magnitude of association meta-analyses

${ }^{b}$ More information in the appendix

${ }^{\mathrm{c}}$ Proportion meta-analyses

${ }^{\mathrm{d}}$ Proportion meta-analyses (Subgroup analyses)

${ }^{\mathrm{e}}$ Test for between-subgroup differences

${ }^{\mathrm{f}}$ Effect of study covariates on the prevalence of depression, anxiety or stress among OLP patients. A meta-regression coefficient $>0$ indicates a greater impact of covariates on the prevalence of mental disorders in patients with OLP

${ }^{\mathrm{g}} P$ value \pm standard error after 10,000 permutations based on Monte Carlo simulation

${ }^{\text {h}}$ Proportion of between-study variance explained (adjusted $\mathrm{R}^{2}$ statistic) using the residual maximum likelihood (REML) method. A negative number for proportion of heterogeneity explained reflects no heterogeneity explained

meta-analysis [12] presents critically low methodological quality, according to AMSTAR2, which is essentially due to a significant selection bias derived from having designed a low-sensitive search strategy that only identified 16 studies for analysis-a number of studies considerably lower than the 51 studies included in our present meta-analysis. Therefore, the results of Jalenque et al. [12] seem incomplete.

Our results also interestingly reveal that the studies reporting the higher prevalences of depression also report the higher frequencies of anxiety $(p=0.001)$, which seems to indicate a comorbidity among depression, anxiety, and OLP. Specialists involved in the diagnosis and treatment of OLP, especially dentists-as they are in the first line of care for patients with oral diseases-must be aware of these important comorbidities in order to implement appropriate measures that allow patients with OLP to receive the specialized care required for these emotional disorders. As previously mentioned, it may not be straightforward for a dentist to bring out psychological disorders in patients with OLP, whose main reason for consultation is the presence of oral mucosal lesions. In the experience of the authors (MAGM, SW), patients often do not disclose these conditions out of shame, feelings of stigmatization or fear of family incomprehension, and the adverse effects of psychotropic drugs. Occasionally, patients consider their emotional disorders as non-pathological situations derived from stress or everyday problems in life. Finally, sometimes dentists may not feel themselves authorized or trained to identify and refer patients to a psychiatrist or psychologist. The treatment of psychological disorders is a relevant issue since many of them considerably decrease the quality of life of the patient, which in itself can be notably deteriorated by OLP. 
Table 4 Prevalence and magnitude of association of stress in patients with OLP and associated factors

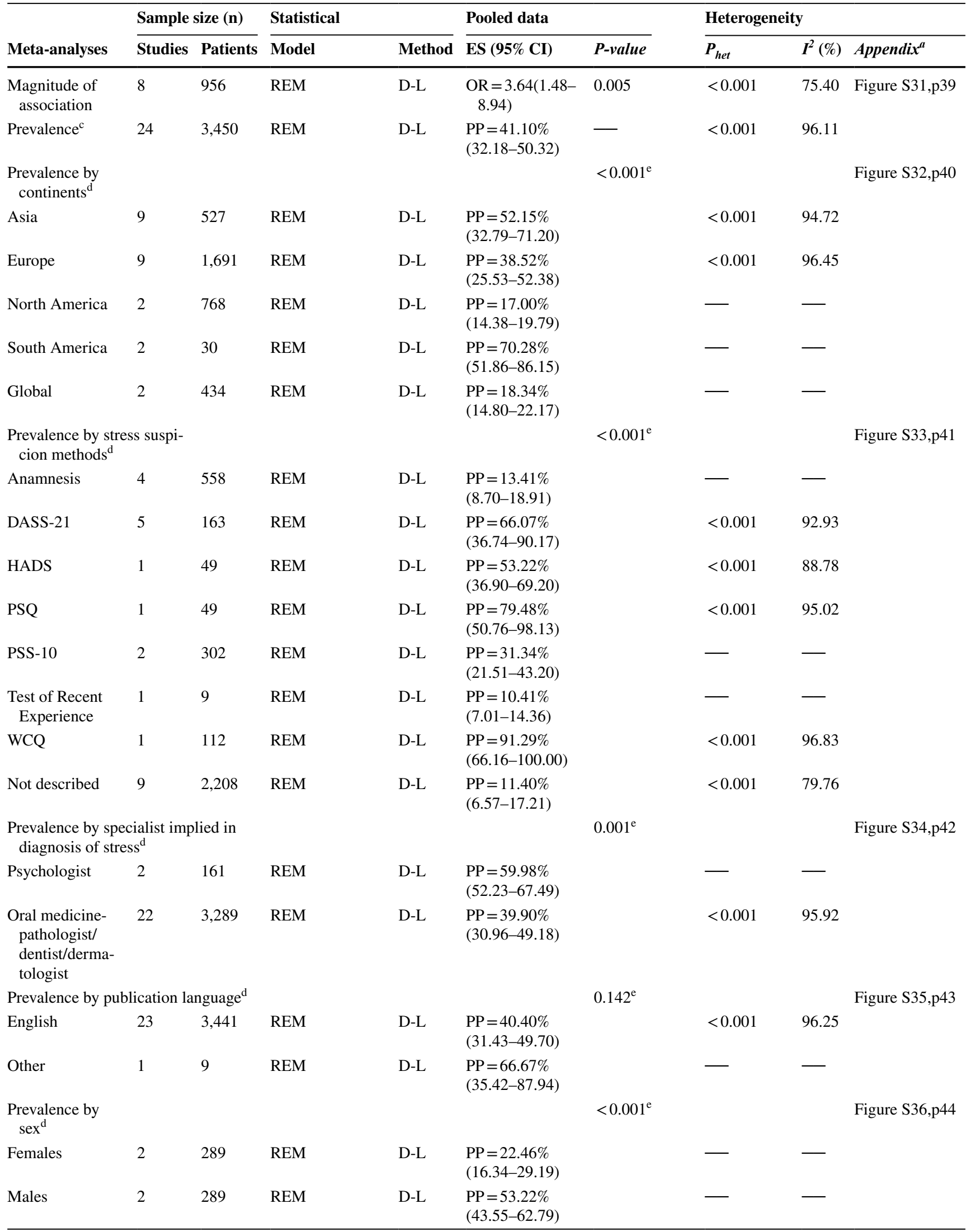


Table 4 (continued)

\begin{tabular}{|c|c|c|c|c|c|c|c|c|}
\hline \multirow[b]{2}{*}{ Meta-analyses } & \multicolumn{2}{|c|}{ Sample size (n) } & Statistical & \multicolumn{2}{|l|}{ Pooled data } & \multicolumn{3}{|c|}{ Heterogeneity } \\
\hline & Studies & Patients & Method & ES $(95 \% \mathrm{CI})$ & P-value & $P_{\text {het }}$ & $I^{2}(\%)$ & Appendix ${ }^{a}$ \\
\hline \multicolumn{9}{|c|}{ Prevalence. Univariable meta-regression. ${ }^{\mathrm{f}}$} \\
\hline $\begin{array}{l}\text { Sex (\% OLP } \\
\text { females) }\end{array}$ & 22 & 3,267 & $\begin{array}{l}\text { random-effects meta- } \\
\text { regression }\end{array}$ & $\begin{array}{l}\text { Coef }=-.0004 \\
(-.0078 \text { to } .0069)\end{array}$ & $\begin{array}{l}0.89 \pm \\
0.010^{g}\end{array}$ & $\begin{array}{l}\text { het }_{\text {explained }}= \\
-7.13 \% \mathrm{~h}^{\mathrm{h}}\end{array}$ & & Figure S37, p.45 \\
\hline $\begin{array}{l}\text { Age (mean age of } \\
\text { OLP patients) }\end{array}$ & 19 & 3,153 & $\begin{array}{l}\text { random-effects meta- } \\
\text { regression }\end{array}$ & $\begin{array}{l}\text { Coef }=-.0065 \\
(-.0247 \text { to } .0118)\end{array}$ & $\begin{array}{l}0.49 \pm \\
0.016^{\mathrm{g}}\end{array}$ & $\begin{array}{l}\text { het }_{\text {explained }}= \\
-8.56 \%{ }^{\mathrm{h}}\end{array}$ & & Figure S38, p.46 \\
\hline $\begin{array}{l}\text { Tobacco (\% OLP } \\
\text { smokers) }\end{array}$ & 13 & 1,210 & $\begin{array}{l}\text { random-effects meta- } \\
\text { regression }\end{array}$ & $\begin{array}{l}\text { Coef }=-.0046 \\
(-.0146 \text { to } .0054)\end{array}$ & $\begin{array}{l}0.35 \pm \\
0.015^{\mathrm{g}}\end{array}$ & $\begin{array}{l}\text { het }_{\text {explained }}= \\
-5.86 \%{ }^{\mathrm{h}}\end{array}$ & & Figure S39, p.47 \\
\hline $\begin{array}{l}\text { Alcohol (\% OLP } \\
\text { drinkers) }\end{array}$ & 5 & 847 & $\begin{array}{l}\text { random-effects meta- } \\
\text { regression }\end{array}$ & $\begin{array}{l}\text { Coef }=-.0016 \\
(-.0194 \text { to } .0163)\end{array}$ & $\begin{array}{l}0.75 \pm \\
0.014^{\mathrm{g}}\end{array}$ & $\begin{array}{l}\text { het }_{\text {explained }}= \\
-40.88 \% \mathrm{~h}\end{array}$ & & Figure S40, p.48 \\
\hline $\begin{array}{l}\text { Red lesions } \\
\text { (\%OLP } \\
\text { patients) }\end{array}$ & 15 & 2,839 & $\begin{array}{l}\text { random-effects meta- } \\
\text { regression }\end{array}$ & $\begin{array}{l}\text { Coef }=-.0013 \\
(-.0051 \text { to } .0024)\end{array}$ & $\begin{array}{l}0.44 \pm \\
0.016^{\mathrm{g}}\end{array}$ & $\begin{array}{l}\text { het }_{\text {explained }}= \\
-9.05 \% \mathrm{~h}\end{array}$ & & Figure S41, p.49 \\
\hline Year & 24 & 3,450 & $\begin{array}{l}\text { random-effects meta- } \\
\text { regression }\end{array}$ & $\begin{array}{l}\text { Coef }=-.0044 \\
(-.0082 \text { to } .0170)\end{array}$ & $0.48 \pm 0.016^{\mathrm{g}}$ & $\begin{array}{l}\text { het }_{\text {explained }}= \\
-3.36 \%^{\mathrm{h}}\end{array}$ & & Figure $S 42$, p. 50 \\
\hline HDI & 24 & 3,450 & $\begin{array}{l}\text { random-effects meta- } \\
\text { regression }\end{array}$ & $\begin{array}{c}\text { Coef }=-.5188 \\
(-1.4102 \text { to } \\
.3726)\end{array}$ & $0.241 \pm 0.014^{g}$ & $\begin{array}{l}\text { het }_{\text {explained }}= \\
0.68 \%^{\mathrm{h}}\end{array}$ & & Figure $S 43$, p. 51 \\
\hline RoB & 24 & 3,450 & $\begin{array}{l}\text { random-effects meta- } \\
\text { regression }\end{array}$ & $\begin{array}{l}\text { Coef }=-.2666 \\
(-.5855 \text { to } .0522)\end{array}$ & $\begin{array}{l}0.11 \pm \\
0.001^{g}\end{array}$ & $\begin{array}{l}\text { het }_{\text {explained }}= \\
10.71 \%^{\mathrm{h}}\end{array}$ & & Figure $S 44$, p.52 \\
\hline
\end{tabular}

Abbreviations: Stat., statistical; Wt, method of weighting; $P P$, pooled proportion; $C I$, confidence intervals; REM, random-effects model; $D$ - $L$, DerSimonian and Laird method; $O L P$, oral lichen planus; DASS-21, depression, anxiety and stress scale-21 items; HADS, hospital and anxiety depression scale; HDI, Human Development Index; RoB, Risk of Bias; PSQ, General Perceived Stress Questionnaire; PSS-10, Perceived Stress Scale; $W C Q$, Ways of Coping Questionnaire

${ }^{a}$ Magnitude of association meta-analyses

${ }^{b}$ More information in the appendix

${ }^{\mathrm{c}}$ Proportion meta-analyses

${ }^{\mathrm{d}}$ Proportion meta-analyses (Subgroup analyses)

${ }^{\mathrm{e}}$ Test for between-subgroup differences

${ }_{\mathrm{f}}^{\mathrm{f}}$ Effect of study covariates on the prevalence of depression, anxiety or stress among OLP patients. A meta-regression coefficient $>0$ indicates a greater impact of covariates on the prevalence of mental disorders in patients with OLP

${ }^{\mathrm{g}} P$ value \pm standard error after 10,000 permutations based on Monte Carlo simulation

${ }^{\text {h}}$ Proportion of between-study variance explained (adjusted $R^{2}$ statistic) using the residual maximum likelihood (REML) method. A negative number for proportion of heterogeneity explained reflects no heterogeneity explained

Furthermore, although there is no scientific evidence on the subject, hypothetically, in some patients, the control of psychological disorders could also improve the OLP control, since it is frequent to note the worsening of OLP symptoms in periods in which the emotional symptoms increase. The training and insight of the dentist will make it possible to suspect the presence of emotional factors, and through an anamnesis carried out with subtlety, the patient will recognize the existence of these abnormalities.

According to our qualitative evaluation using a specific critical appraisal checklist designed by the Joanna Briggs Institute for systematic reviews addressing prevalence questions, although our included primary-level studies had similar study design, all were not conducted with the same rigor. Most potential biases were caused by the failure considering three specific items (i.e., Q2, Q9, and Q10). To meet Q2, future studies should recruit study participants in an appropriate way, always reporting how sampling was performed, and preferably using random sampling methods. On the other hand, Q9 and Q10, respectively, target biases due to potentially confounding factors and non-identified subpopulations, both items sharing similarities. Future studies should be better designed, correctly measuring and clearly reporting data related to age, sex, OLP type and location of lesions, medical history, and tobacco/alcohol habits. Furthermore, studies do not report treatment for these conditions or if OLP patient relapses are precipitated by worsening of the emotional status of patients. On the other hand, future studies should also focus on these issues. On the other hand, we tested the influence of risk of bias on the overall results using meta-regression, and no significant differences were observed. The overall results do not depend on the influence of the subset of studies with lowest quality, increasing the quality of evidence of the results reported 
Table 5 Recommendations for conducting future studies on OLP and mental disorders

1) Samples must be representative of the target population (i.e., OLP). Primary-level studies must clearly inform about the origin of the sample (general population, hospitals or specialized centers, dental schools, private offices)

2) OLP patients should be recruited in an appropriate way. The methods section should report how sampling was performed; random sampling from a population is strongly encouraged

3) An adequate OLP sample size is imperative to guarantee the representativeness of the population with OLP and to ensure a precise final estimate. Preliminary sample size calculation should be conducted to determine an adequate sample size

4) OLP subjects should be described in detail. Their demographic and clinicopathological characteristics should be registered during follow-up. Studies should include data related to sex, age, clinical appearance and location of the lesions, medical history, habits, and histopathological data of OLP

Depression, anxiety, and stress should be measured in an objective way, using standard criteria. Specialists (i.e., psychologists and psychiatrists) should collaborate with dentists in future studies to make an appropriate diagnosis

5) Studies should report comprehensive data on follow-up periods and dropout rates. Long follow-up periods are encouraged. Studies should describe attempts to gather information on patients who dropped out, their features, and follow-up reasons

6) Studies must clearly report the OLP diagnostic criteria used, which should be agreed upon by groups of experts and in any case derived from scientific publications, preferably systematic reviews and meta-analyses (e.g., Gonzalez-Moles et al. 2020, [1]). It is recommended to include clinical and histopathological criteria in the diagnosis

7) It should be reported how the diagnosis was conducted (trained or educated authors involved, inter-agreement scoring [e.g., Cohen's kappa statistic], more than one data collector, and justifications for diagnosis methods chosen and explicit methods)

8) The statistical analysis must be appropriate to achieve the objectives and supported by clear presentation of data. The reporting of prevalence and incidence estimates on depression, anxiety and/or stress should be accompanied by their confidence intervals

9) It is important to identify all potentially confounding factors (exclusion and/or differentiation of oral lichenoid reactions [by drugs or contact with dental materials], clear definitions and characterization of tobacco and alcohol consumption, sex and age of patients)

10) Potential subpopulations should be comprehensively described in a transparently way, preferably reporting individual patient data (geographical area, ethnia, sex, age, noxious habits, and singularly the prevalence of mental disorders and other systemic comorbidities)

in our meta-analysis. We strongly encourage future studies assessing the prevalence of psychological disorders in OLP, to consider the recommendations given in this systematic review and meta-analysis to improve and standardize future research (Table 5).

Our systematic review and meta-analysis also presents some limitations that should be discussed. First, an inherent limitation of the included studies, as previously commented, was the lack of reporting of relevant datasets that limited the number of observations in secondary analyses (e.g., influence of sex, age, alcohol, tobacco, etc.). Future studies should report datasets in a more rigorous waypreferably individual patient data-given the clinical and methodological relevance of these variables. Second, we observed considerable inter-study heterogeneity. As stated in our study protocol, it was expected, and planned randomeffects models were applied in all meta-analyses to account for heterogeneity. In addition, we conducted several stratified meta-analyses by selecting more homogeneous subgroups, identifying that factors such as geographic areas, specific questionnaires, and the participation of a psychologist or psychiatrist to reach mental disorders' diagnosis constitute important explanatory sources of heterogeneity. Finally, we performed random-effects meta-regression analyses and applied the REML method to produce an adjusted $R^{2}$ statistic, which estimates the proportion of the inter-study variance explained by covariates. This analysis showed that anxiety is a very relevant source of heterogeneity (approximately explaining $75.25 \%$ of heterogeneity), significantly associated with an increased prevalence of depression among OLP patients. Despite the above limitations, the robust nature of our systematic review and meta-analysis is remarkable, as evidenced by our careful process of identification and selection of studies (see flow diagram), where more than 10,000 registers were screened and more than 1,500 papers subject to full-text reading; the absence of restrictions by publication language or date limits; robust qualitative recommendations for future studies on this topic; and potential translational opportunities derived from our comprehensive statistical analysis.

In conclusion, OLP patients suffer depression, anxiety, and stress more frequently than the general population. The physicians involved in the management of OLP, especially dentists, should be aware of these comorbidities in order to implement the appropriate measures for their referral.

Supplementary Information The online version contains supplementary material available at https://doi.org/10.1007/s00784-021-04114-0.

Funding Open Access funding provided thanks to the CRUE-CSIC agreement with Springer Nature. Funding for open access charge: Universidad de Granada / CBUA.

\section{Declarations}

Ethics approval This is a systematic review and no ethical approval was required. 
Informed consent

This is a systematic review and no informed consent was obtained from all individual participants included in the study.

Conflict of interest The authors declare no competing interests.

Open Access This article is licensed under a Creative Commons Attribution 4.0 International License, which permits use, sharing, adaptation, distribution and reproduction in any medium or format, as long as you give appropriate credit to the original author(s) and the source, provide a link to the Creative Commons licence, and indicate if changes were made. The images or other third party material in this article are included in the article's Creative Commons licence, unless indicated otherwise in a credit line to the material. If material is not included in the article's Creative Commons licence and your intended use is not permitted by statutory regulation or exceeds the permitted use, you will need to obtain permission directly from the copyright holder. To view a copy of this licence, visit http://creativecommons.org/licenses/by/4.0/.

\section{References}

1. González-Moles MÁ, Ramos-García P, Warnakulasuriya S (2020) An appraisal of highest quality studies reporting malignant transformation of oral lichen planus based on a systematic review. Oral Dis. https://doi.org/10.1111/odi.13741

2. González-Moles MÁ, Warnakulasuriya S, González-Ruiz I et al (2020) Worldwide prevalence of oral lichen planus: a systematic review and meta-analysis. Oral Dis. https://doi.org/10.1111/odi. 13323

3. Warnakulasuriya S, Kujan O, Aguirre-Urizar JM et al (2020) Oral potentially malignant disorders: a consensus report from an international seminar on nomenclature and classification, convened by the WHO Collaborating Centre for Oral Cancer. Oral Dis. https:// doi.org/10.1111/odi.13704

4. Ramos-García P, Ángel González-Moles M, Warnakulasuriya $S$ (2021) Oral cancer development in lichen planus and related conditions -3.0 evidence level-: a systematic review of systematic reviews. Oral Dis. https://doi.org/10.1111/odi.13812

5. González-Moles MÁ, Ruiz-Ávila I, González-Ruiz L et al (2019) Malignant transformation risk of oral lichen planus: a systematic review and comprehensive meta-analysis. Oral Oncol 96:121-130. https://doi.org/10.1016/j.oraloncology.2019.07.012

6. Hampf BG, Malmström MJ, Aalberg VA et al (1987) Psychiatric disturbance in patients with oral lichen planus. Oral Surg Oral Med Oral Pathol 63:429-432. https://doi.org/10.1016/00304220(87)90254-4

7. Kövesi G, Bánóczy J (1973) Follow-up studies in oral lichen planus. Int J Oral Surg 2:13-19. https://doi.org/10.1016/s03009785(73)80012-2

8. Rojo-Moreno JL, Bagán JV, Rojo-Moreno J et al (1998) Psychologic factors and oral lichen planus. A psychometric evaluation of 100 cases. Oral Surg Oral Med Oral Pathol Oral Radiol Endod 86:687-691. https://doi.org/10.1016/s1079-2104(98)90205-0

9. Chaudhary S (2004) Psychosocial stressors in oral lichen planus. Aust Dent J 49:192-195

10. Lundqvist EN, Wahlin YB, Bergdahl M, Bergdahl J (2006) Psychological health in patients with genital and oral erosive lichen planus. J Eur Acad Dermatol Venereol 20:661-666. https://doi. org/10.1111/j.1468-3083.2006.01559.x

11. Cerqueira JDM, Moura JR, Arsati F, et al (2018) Psychological disorders and oral lichen planus: a systematic review. J Investig Clin Dent 9:e12363. https://doi.org/10.1111/jicd.12363
12. Jalenques I, Lauron S, Almon S, et al (2020) Prevalence and odds of signs of depression and anxiety in patients with lichen planus: systematic review and meta-analyses. Acta Derm Venereol 100:adv00330. https://doi.org/10.2340/00015 555-3660

13. Ramos-Garcia P, Roca-Rodriguez MDM, Aguilar-Diosdado M, Gonzalez-Moles MA (2021) Diabetes mellitus and oral cancer/ oral potentially malignant disorders: a systematic review and meta-analysis. Oral Dis 27:404-421. https://doi.org/10.1111/odi. 13289

14. Petti S, Rabiei M, De Luca M, Scully C (2011) The magnitude of the association between hepatitis $\mathrm{C}$ virus infection and oral lichen planus: meta-analysis and case control study. Odontology 99:168-178. https://doi.org/10.1007/s10266-011-0008-3

15. Lodi G, Pellicano R, Carrozzo M (2010) Hepatitis C virus infection and lichen planus: a systematic review with meta-analysis. Oral Dis 16:601-612. https://doi.org/10.1111/j.1601-0825.2010. 01670.x

16. Li D, Li J, Li C et al (2017) The association of thyroid disease and oral lichen planus: a literature review and meta-analysis. Front Endocrinol (Lausanne) 8:310. https://doi.org/10.3389/fendo.2017. 00310

17. Miyagaki T, Sugaya M, Miyamoto A, et al (2011) Oral erosive lichen planus associated with thymoma treated with etretinate. Australas J Dermatol 54:e25-e27. https://doi.org/10.1111/j.14400960.2011.00818.x

18. Higgins JP, Green S (2008) Cochrane Handbook for Systematic Reviews of Interventions: Cochrane Book Series. In: Cochrane Handb. Syst. Rev. Interv. Cochrane B. Ser.

19. Shea BJ, Reeves BC, Wells G, et al (2017) AMSTAR 2: a critical appraisal tool for systematic reviews that include randomised or non-randomised studies of healthcare interventions, or both. BMJ J 4008. https://doi.org/10.1136/bmj.j4008

20. Stroup DF, Berlin JA, Morton SC et al (2000) Meta-analysis of observational studies in epidemiology: a proposal for reporting. J Am Med Assoc 283:2008-2012. https://doi.org/10.1001/jama. 283.15.2008

21. Moher D, Liberati A, Tetzlaff J, et al (2009) Preferred reporting items for systematic reviews and meta-analyses: the PRISMA statement. PLoS Med 6:e1000097. https://doi.org/10.1371/journ al.pmed. 1000097

22. Shamseer L, Moher D, Clarke M, et al (2015) Preferred reporting items for systematic review and meta-analysis protocols (PRISMA-P) 2015: elaboration and explanation. BMJ 350:g7647

23. Aromataris E MZ (2020) JBI Manual for Evidence Synthesis. JBI

24. Agresti A, Coull BA (1998) Approximate is better than "exact" for interval estimation of binomial proportions. Am Stat 52:119-126. https://doi.org/10.1080/00031305.1998.10480550

25. Freeman M, Tuckey J (1950) Transformations Related to the Angular and the Square Root. Ann Math Stat 21:607-611. https://doi.org/10.1214/aoms/1177729756

26. DerSimonian R, Laird N (1986) Meta-analysis in clinical trials. Control Clin Trials 7:177-188. https://doi.org/10.1016/01972456(86)90046-2

27. Higgins JPT, Thompson SG (2002) Quantifying heterogeneity in a meta-analysis. Stat Med 21:1539-1558. https://doi.org/10. 1002/sim. 1186

28. Higgins JPT, Thompson SG, Deeks JJ, Altman DG (2003) Measuring inconsistency in meta-analyses. BMJ 327:557-560. https://doi.org/10.1136/bmj.327.7414.557

29. Borenstein M, Higgins JPT (2013) Meta-analysis and subgroups. Prev Sci 14:134-143. https://doi.org/10.1007/ s11121-013-0377-7

30. Thompson SG, Higgins JPT (2002) How should meta-regression analyses be undertaken and interpreted? Stat Med 21:15591573. https://doi.org/10.1002/sim.1187 
31. Thompson SG, Sharp SJ (1999) Explaining heterogeneity in meta-analysis: a comparison of methods. Stat Med 18:26932708. https://doi.org/10.1002/(sici)1097-0258(19991030)18: 20\%3c2693::aid-sim235\%3e3.0.co;2-v

32. Higgins JPT, Thompson SG (2004) Controlling the risk of spurious findings from meta-regression. Stat Med 23:1663-1682. https://doi.org/10.1002/sim.1752

33. Viechtbauer W, Cheung MW-L (2010) Outlier and influence diagnostics for meta-analysis. Res Synth Methods 1:112-125. https://doi.org/10.1002/jrsm.11

34. Sterne JAC, Sutton AJ, Ioannidis JPA, et al (2011) Recommendations for examining and interpreting funnel plot asymmetry in meta-analyses of randomised controlled trials. BMJ 343:d4002

35. Egger M, Davey Smith G, Schneider M, Minder C (1997) Bias in meta-analysis detected by a simple, graphical test. BMJ 315:629-634

36. Duval S, Tweedie R (2000) A non-parametric "trim and fill" method of assessing publication bias in meta-analysis. J Am Stat
Assoc 95:89-98. https://doi.org/10.1080/01621459.2000.10473 905

37. Kalkur C, Sattur AP, Guttal KS (2015) Role of depression, anxiety and stress in patients with oral lichen planus: a pilot study. Indian J Dermatol 60:445-449. https://doi.org/10.4103/0019-5154.159625

38. Birckel E, Lipsker D, Cribier B (2020) Efficacy of photopheresis in the treatment of erosive lichen planus: a retrospective study. Ann Dermatol Venereol 147:86-92. https://doi.org/10.1016/j. annder.2019.02.011

39. Shea BJ, Reeves BC, Wells G et al (2017) AMSTAR 2: a critical appraisal tool for systematic reviews that include randomised or non-randomised studies of healthcare interventions, or both. BMJ 358:j4008. https://doi.org/10.1136/bmj.j4008

Publisher's Note Springer Nature remains neutral with regard to jurisdictional claims in published maps and institutional affiliations. 